\title{
Glance Into Solid-State Transformer Technology: A Mirror For Possible Research Areas
}

\author{
Bashir Musa Umar ${ }^{1, *}\left(\mathbb{0}\right.$, Jibril Yusf², Boyi Jimoh² ${ }^{2}$ Abdullahi Bala Kunya ${ }^{2}$, Yusuf Abubakar Maiwada ${ }^{3}$, \\ Safiyu Aliyu', Musa Mohammed ${ }^{2}$ (1)
}

${ }^{1}$ Centre for Energy Research and Training, Ahmadu Bello University (A.B.U), Zaria-Nigeria

${ }^{2}$ Department of Electrical Engineering, A.B. U. Zaria-Nigeria

${ }^{3}$ Electrical/Electronic Engineering Department, Hassan Usman Katsina Polytechnic, Katsina-Nigeria

\begin{abstract}
Solid-State Transformer (SST), a power electronics based transformer is an emerging technology in electric power system. The transformer is being investigated to completely replace existing Line/Low Frequency Transformer (LFT). SST is composed of either of the two topologies: AC-DC-AC, two steps approach; or AC-AC, single-step approach. The two steps approach consists of three stages: AC-DC; DC-DC; and DC-AC stages. The DC-DC stage is made up of a boost DC-DC converter, a DC-AC inverter and a High Frequency Transformer, HFT. Therefore, SST performs the tasks of LFT by means of power electronic converters and HFT. The main essence of SST is to provide solution to the problem of bulkiness and heaviness of the LFT in the power distribution network. This is with the view to providing reduction in construction cost, cost of maintenance and transportation. The power electronics transformer provides numerous advantages which are grouped into: The transformer has high power density; it functions in blackouts and brownouts; and it provides easy means of distributed renewable energy integration into associated grid. Therefore, this paper provides a glance into the technology of the SST for its better understating and promotion of research activities in the area.
\end{abstract}

Key words: Solid-state transformer, Line frequency Transformer, converters, High frequency transformer.

\section{INTRODUCTION}

Power Electronics (PE) is one of the most emerging areas of Electrical Engineering [1]. The technology is a branch of engineering that combines fields of electrical power, electronics and control [1]. PE is the technology associated with efficient conversion, control and conditioning of electric power by static means from its available input into a desired electrical output form [2]. The In other words, the technology is concerns with application of solid-state electronics to the control and conversion of electric power. PE enables efficient and flexible control over power from the grid. Therefore, this technology has been attracting research attention globally [3]. The research in Power Electronics is mainly aim at miniaturization of practical electronic applications, and effectiveness of cost and dynamic performance of electrical equipment[4]. One of the areas of application of PE is the transformer.

Low/Line Frequency Transformer (LFT) otherwise known as conventional transformer had been in use since 1880 s. Since when it was invented, the transformer has been significantly improved. However, basic concepts of the transformer remain unchanged[5] and [6]. The transformer is relatively efficient, reliable etc. However, LFT gives losses at no load condition. This implies that it consumes power even if no load is connected at its secondary side. It only allows for unidirectional power flow. LFT is sensitive to harmonics causing it to heat up and to DC offset load imbalances, which causes them to saturate. In some of the LFTs, oil is used as a coolant, which can cause pose fear due to possibility of fire hazards and attracts environmental concerns [7]. In addition, the LFT is associated with bulky size and heavy weight. These disadvantages, coupled with the fact that the emerging grid in electric power system requires new functionalities, controllability and flexibility from the distribution make the LFT undesirable [8]. These and many more constraints of LFT permit researchers to conclude that the conventional transformer cannot effectively meet up with challenges of modern grid [4]. Therefore, a smart power electronics based transformer (Solid-State Transformer, SST) has been investigated. The SST has relatively reduced size and weight due to use of High Frequency Transformer (HFT) in its design. Additional advantages of SST over the LFT are: mitigation of flicker, on-demand reactive power support to grid, power quality improvement, fast control of bidirectional active power flow (Forward and reverse flow), protection from system disruptions and overloads, provision for energystorage capacity among others [9] and [10].

$\begin{array}{ll}\text { Received } & \text { : July 21, 2020 } \\ \text { Revised } & \text { : Septermber 23, 2020 } \\ \text { Accepted } & \text { : October 04, 2020 }\end{array}$




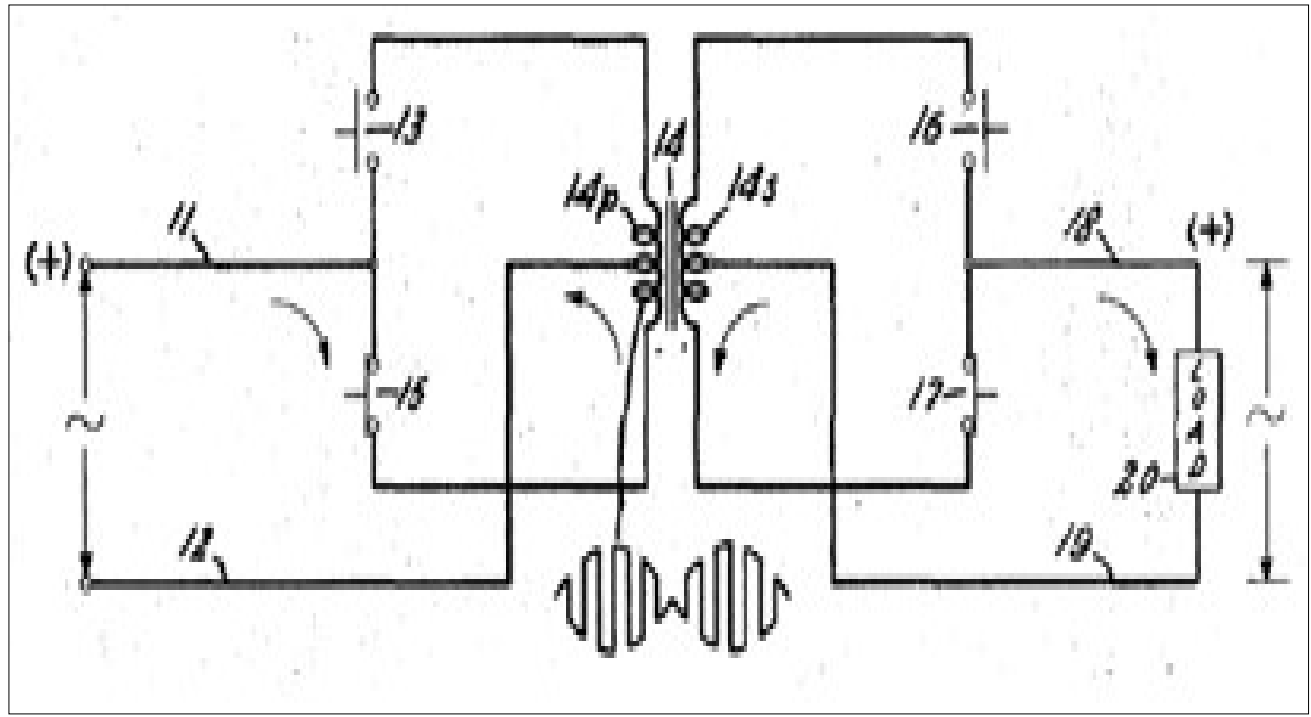

Fig. 1. Circuit Diagram of Electronic Transformer [9]

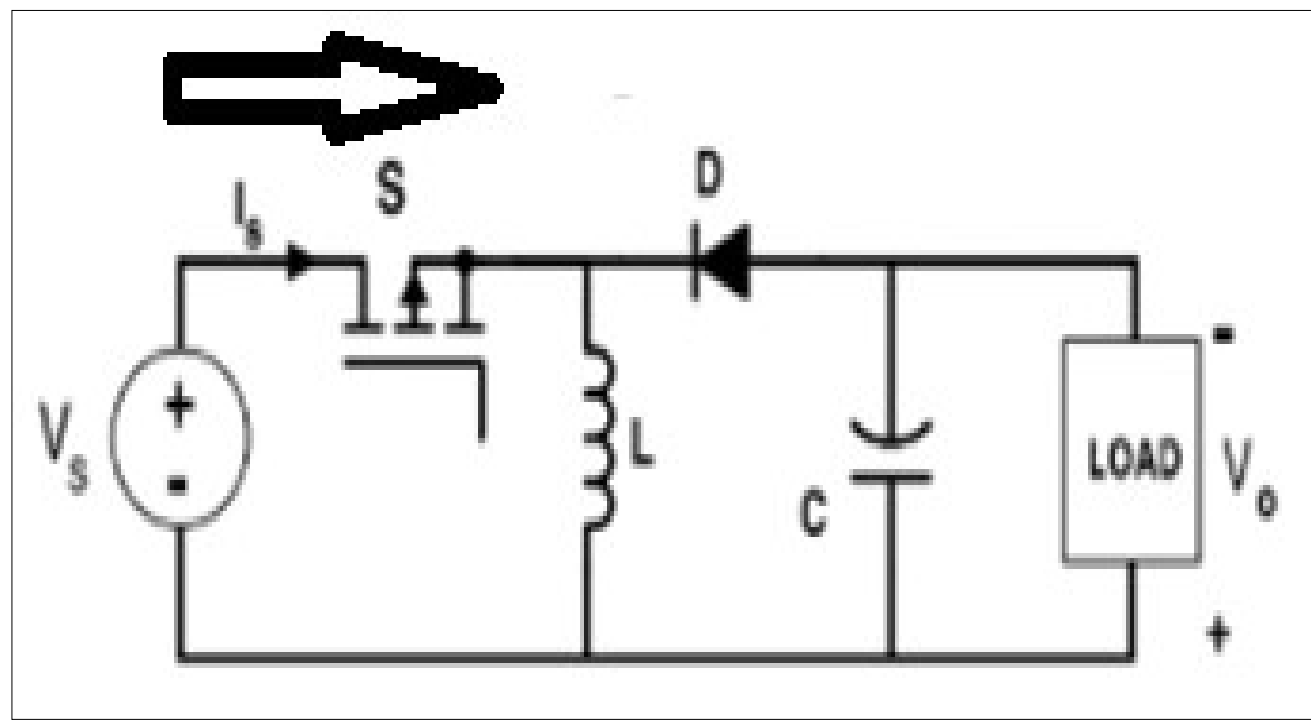

Fig. 2. Modified Circuit Diagram of Electronic Transformer [9]

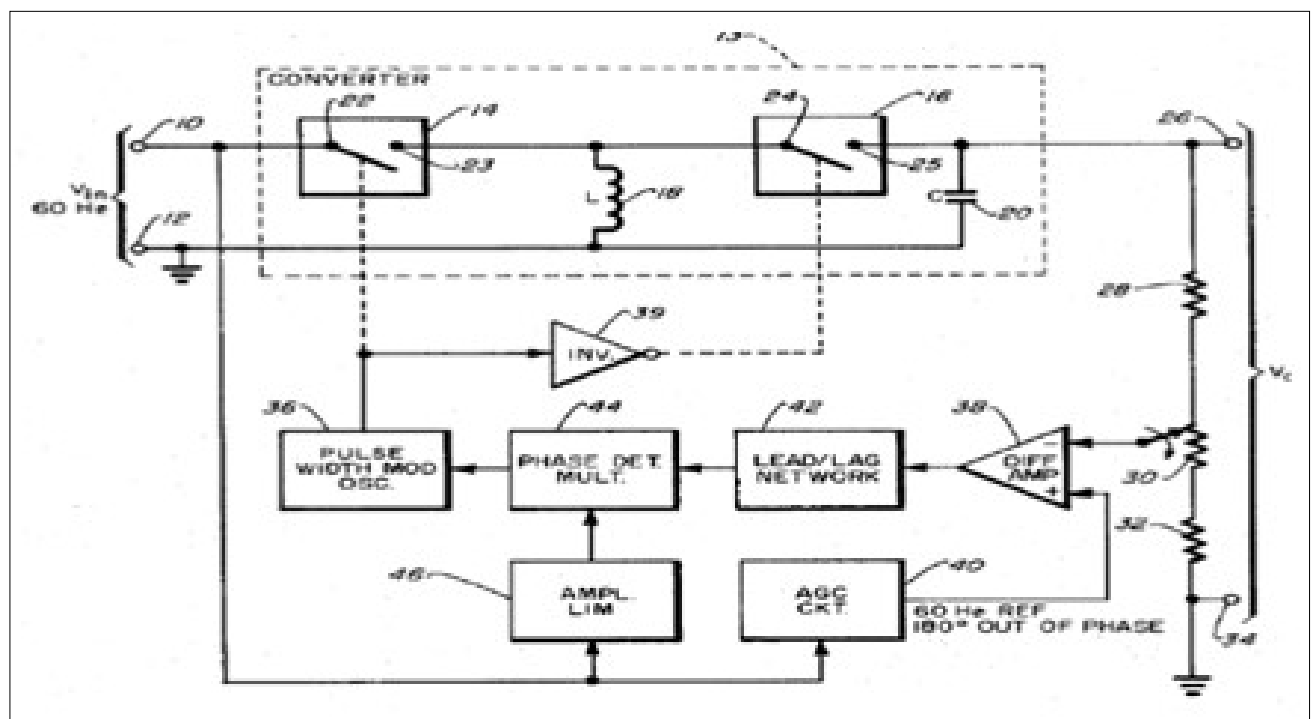

Fig. 3. Circuit Diagram of Intelligent Universal Transformer [9] 


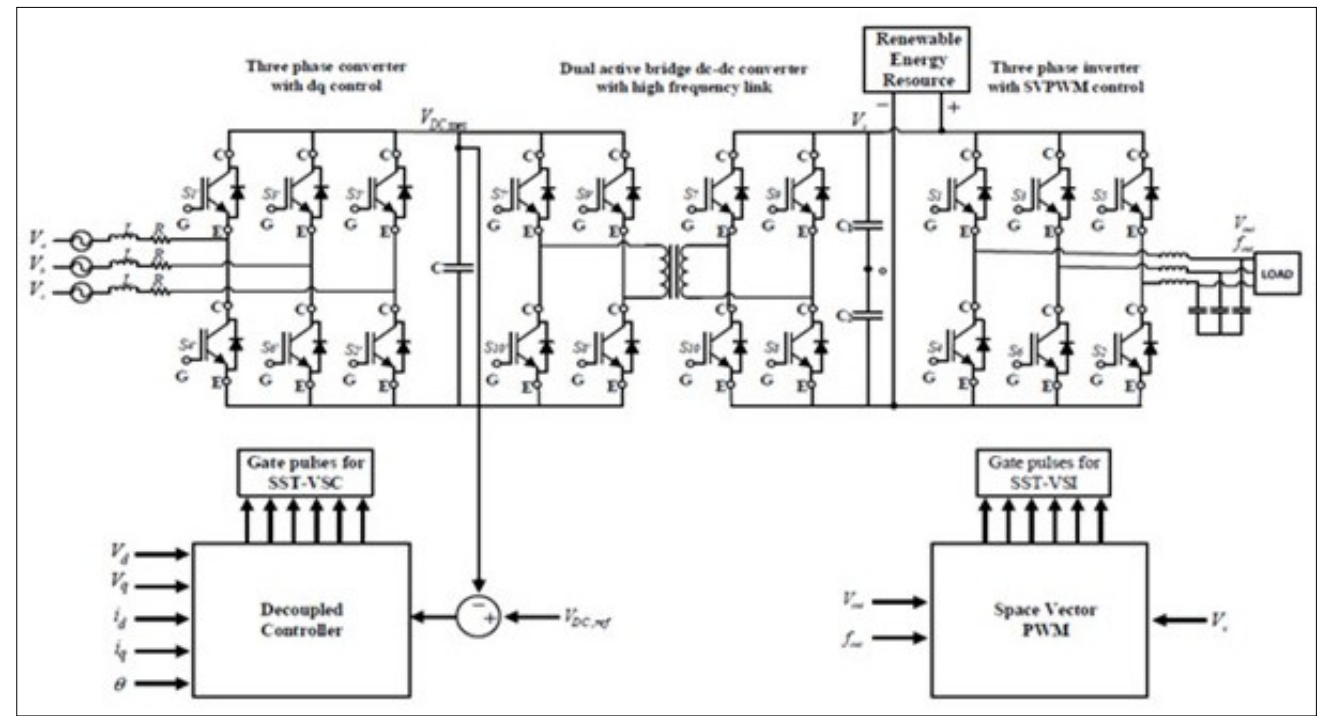

Fig. 4. Circuit Diagram of SST [13]

This paper conducted a research on evolution trend of SST, Its concept architecture, its conversion stages, HFT, and provides a general overview of the SST technology. Also, Obstacle of the SST to universal acceptance and future research possibilities are highlighted by the paper. Conclusion is finally drawn at the end of the paper.

\section{EVOLUTION TREND OF SST}

Concept of SST was first discovered in 1968 by McMurray, a Los Angeles born Engineer who worked with General Electric Company [9]. The discovery of the Electronic Transformer (ET) as it was then called was announced in 1970 [11]. Circuit diagram of the ET is as shown in Figure 1.

The ET circuit was later modified to include inverse-paralleled pairs of Turn-OFF switches at 50\% modulation index of both input and output stages by the inventor as shown in Figure 2.

In 1980, Brooks proposes a SST design which was known as Intelligent Universal Transformer (IUT). IUT was produced in 1982 by Electric Power Research Institute (EPRI) [12]. The IUT circuit diagram is as shown in Figure 3.

Several names were given to SST by many Institutes and researchers: Power Electronics Transformer (PET); Energy Control Center (ECC); Energy Router etc. [9]

\section{SST CONSEPT}

The SST can conveniently replace the LFT after addressing most of the basic challenges it has and provide the following functionalities in the electric grid [14]: AC or DC bidirectional power flow; reduced size and weight as a result of use HFT in its construction; correction of power factor, fast fault detection and protection e.t.c [12]. These in addition to the functions of the LFT it also offers: provision of galvanic isolation; and step up/down of input voltage. The additional functionalities SST can provide will enable it solve challenges of smart grid [15]. Opportunity to condition the power flow as provided by the SST will enable easy integration and subsequent management of Renewable Energy Sources, RES in the grid and handling of different loads. The traction systems will be blessed of achieving high performances as a result of reduced size and weight of the SST if it is employed to work with the systems. Additionally, cost of transformer, its transportation and maintenance will be significantly reduced.

The SST circuit is composed of two or more static converters isolated by a transformer that operates at frequency considerably higher than the conventional $50 / 60 \mathrm{~Hz}$. The SST concept is as represented in Figure 5 [8].

Comparison between SST and LFT based on some selected transformer parameters is as shown in Table 1.

\section{SST ARCHITECTURE}

Many SST architectures exist. The architectures have different design features, and circuit performances [16]. The SST architectures are classified into four groups. These are [4] and [11]: i) Single stage without Direct Current, DC link; ii) two stages with low voltage DC link; iii) two stages with medium voltage DC link; and iv) Three stages with low and medium voltage DC link. Circuit diagrams of these groups are as shown in Figures 6-9.

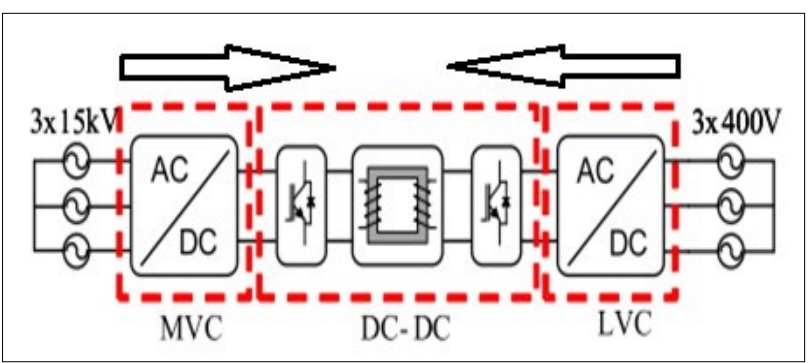

Fig. 5. Basic Concept of SST 


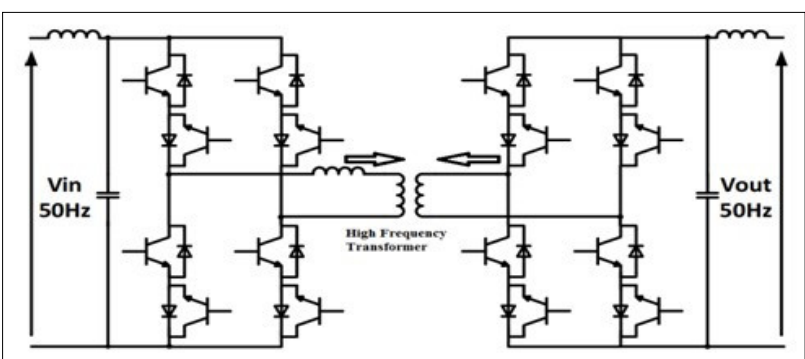

Fig. 6. Circuit Diagram of Single Stage SST without DC Link

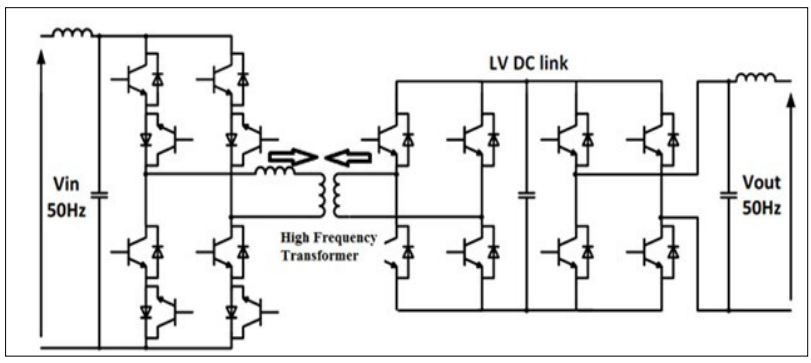

Fig. 7. Circuit Diagram of Single Stage with Low Voltage (LV) DC Link

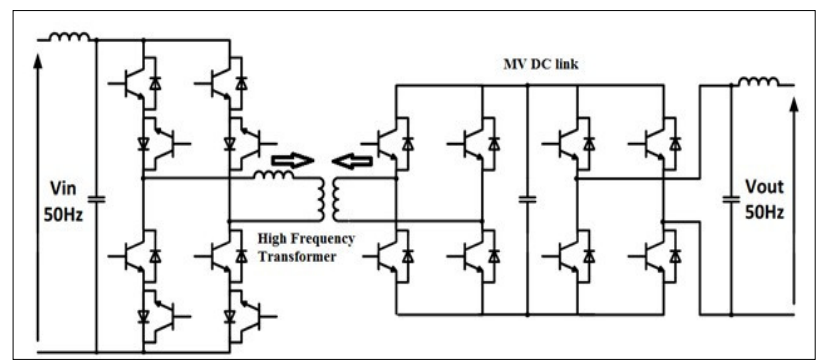

Fig. 8. Circuit Diagram of Single Stage with Medium Voltage (MV) DC Link

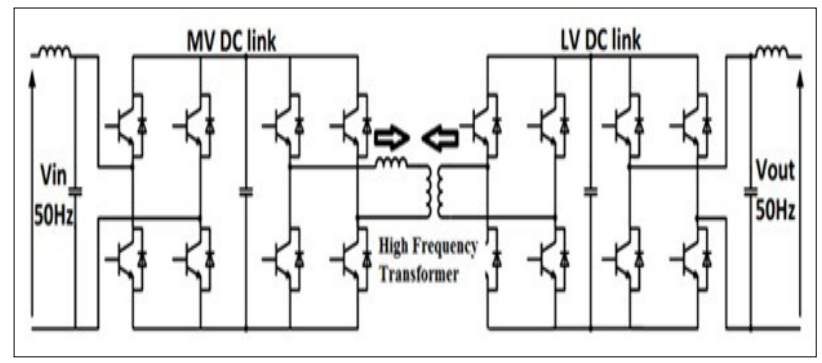

Fig. 9. Circuit Diagram of Single Stage with Medium Voltage (MV) and Low Voltage DC Links

\section{OVERVIEW OF SST CONVERSION STAGES}

There are three main conversion stages in the SST. These are [16] and [17]: i) AC-DC conversion stage (Rectifier); ii) DC-DC conversion stage; and DC-AC conversion stage (Inverter).

The AC-DC stage is the first stage of SST and is responsible for the connection of MV AC side of the distribution network and the MV DC link [16]. Multilevel topology is mainly used. The commonly used multilevel are: i) cascade H-bridge; Neutral Point Clamped (NPC) otherwise known as diode-clamped; and iii) Flying capacitor converter.
Table 1 Comparison between LFT and SST

\begin{tabular}{|c|c|c|c|}
\hline SNo & Parameter & LFT & SST \\
\hline 1 & $\begin{array}{l}\text { Power } \\
\text { Factor, PF }\end{array}$ & Low PF & $\begin{array}{l}\text { Almost Unity } \\
\text { because of } \mathrm{AD} \text { - } \\
\mathrm{DC} \text { conversion } \\
\text { involved }\end{array}$ \\
\hline 2 & $\begin{array}{l}\text { Size and } \\
\text { weight }\end{array}$ & $\begin{array}{l}\text { Bulky and } \\
\text { heavy }\end{array}$ & $\begin{array}{l}\text { Light and } \\
\text { compact }\end{array}$ \\
\hline 3 & $\begin{array}{l}\text { Circuit } \\
\text { topology }\end{array}$ & $\begin{array}{l}\text { Primary and } \\
\text { secondary } \\
\text { sides are } \\
\text { magnetically } \\
\text { coupled, } \\
\text { therefore, any } \\
\text { parameter } \\
\text { variation in } \\
\text { one side affects } \\
\text { other }\end{array}$ & $\begin{array}{l}\text { The two sides } \\
\text { are } \\
\text { independent } \\
\text { and are being } \\
\text { managed by } \\
\text { proper } \\
\text { converter } \\
\text { control }\end{array}$ \\
\hline 4 & $\begin{array}{l}\text { Voltage } \\
\text { Regulation }\end{array}$ & $\begin{array}{l}\text { Not good for } \\
\text { distribution } \\
\text { LFT }\end{array}$ & $\begin{array}{l}\text { As power flash } \\
\text { current of SST } \\
\text { can be } \\
\text { controlled in } \\
\text { transient, } \\
\text { voltage regula- } \\
\text { tion is better } \\
\text { achieved }\end{array}$ \\
\hline 5 & Losses & $\begin{array}{l}\text { High losses, it } \\
\text { cannot be } \\
\text { implemented } \\
\text { at full load or } \\
\text { maximum effi- } \\
\text { ciency }\end{array}$ & $\begin{array}{l}\text { Efficiency can } \\
\text { be increased } \\
\text { since the } \\
\text { current can be } \\
\text { controlled }\end{array}$ \\
\hline 6 & Harmonics & $\begin{array}{l}\text { High harm } \\
\text { onics due to } \\
\text { use of } \\
\text { saturated core }\end{array}$ & $\begin{array}{l}\text { Reduced } \\
\text { harmonics due } \\
\text { to proper } \\
\text { control of } \\
\text { converter }\end{array}$ \\
\hline 7 & $\begin{array}{l}\text { Fault } \\
\text { detection }\end{array}$ & $\begin{array}{l}\text { External } \\
\text { breaker is } \\
\text { required }\end{array}$ & $\begin{array}{l}\text { Converter is the } \\
\text { breaker }\end{array}$ \\
\hline 8 & $\begin{array}{l}\text { Output } \\
\text { voltage }\end{array}$ & $\begin{array}{l}\text { Depend on } \\
\text { load phase }\end{array}$ & $\begin{array}{l}\text { Constant due to } \\
\text { proper control } \\
\text { of converter }\end{array}$ \\
\hline 9 & $\begin{array}{l}\text { Effect on } \\
\text { Environ- } \\
\text { ment }\end{array}$ & $\begin{array}{l}\text { Oil for cooling } \\
\text { may pollute } \\
\text { environment }\end{array}$ & $\begin{array}{l}\text { No oil is } \\
\text { required as } \\
\text { coolant }\end{array}$ \\
\hline
\end{tabular}

At this stage, the input voltage is the line voltage of the grid for the desired Solid-State Transformer. The DC voltage is calculated using the expression [15]:

$$
V_{D C}=\frac{2}{\frac{2 \pi}{6}}
$$

DC-DC conversion stage comprises three main sections. These are: i) DC-AC converter (Inverter); ii) HFT; and iii) AC-DC converter (Rectifier). This stage is the most crucial stage of the SST. Much architecture for this 
stage is available with different circuit topologies, performances and characteristics. Some of these architectures are: i) Dual Active Bridge (DAB), which consists of two H-bridges isolated by an HFT; ii) Bidirectional Isolated Current Doublers (BICD) converter; and iii) The LLC resonant converter. At the High frequency transformer stage, the peak Line Voltage $\left(\mathrm{V}_{\text {Lpeak }}\right)$ and Root Mean Square (RMS) value of the Line Current $\left(\mathrm{I}_{\mathrm{L} R M S}\right)$ are given as follows $[15]$ :

$$
\begin{aligned}
& V_{L \text { peak }}=\frac{\pi}{3} V_{D C} \\
& I_{L \text { RMS }}=\frac{V A}{V_{R M S} \sqrt{3}}
\end{aligned}
$$

where $V_{D C}$ is the DC voltage at the stage, and VA is the apparent power rating of the SST.

DC-AC conversion stage, here the DC link medium voltage is converted to AC low voltage to drive AC loads. In a situation whereby DC port is required, it is created at the input of this stage.

\section{HIGH FREOUENCY TRANSFORMER}

High frequency Transformer (HFT) is one of the major components of SST [18]. It plays vital role for the performance and overall efficiency of the transformer. It provides the following advantages: electric isolation between the input and output stages; large voltage and current ratios between input and output; size and weight reduction among others [19] and [20]. Due to the fact that the HFT operates at high frequency it is connected to high voltage in case of medium voltage grid, its design is more complex compared to that of the conventional transformer. Use of HFT is responsible for size and volume reduction as well as high power density obtained with the SST. This is in line with the relation between the frequency ' $\mathrm{f}$ ' and overall transformer size as approximated in the following expression [11].

$$
A_{w} X A_{c} \propto \frac{S}{B_{m} X f X J}
$$

where, $A_{c}$ is the core area, $A_{w}$ is the window area $S$ is the output apparent power $B_{m}$ is the peak flux density, and $J$ is the current density of the conductor. A review of the technology of HFT will be presented later in the paper.

In general, while designing SST harmonics are mitigated to the lowest minimum. This action is carried out by an input and output inductors. Value of each of these inductors when multilevel converters are employed in the design, is calculated using the expression [21]:

$$
L=\frac{1}{n} X \frac{V_{D C}}{\Delta I_{\text {peak }} X f_{s w}}
$$

Where $\mathrm{n}$ is a variable that depends on number of levels of converters to be used for the SST and equals 2, if a 4 levels converter is to be used, then $\mathrm{n}=8, \mathrm{f}_{\mathrm{sw}}$ is the switching frequency. The LC filter capacitor value is calculated as follows $[21]$ :

$$
C_{\text {out }}=\frac{1}{\left(2 \pi f_{c}\right)^{2} L_{\text {inv }}}
$$

where $L_{\text {inv }}$ is the value of the output inductor. If input filter capacitor is to be calculated then $L_{\text {inv }}$ in equation (6) will mean input inductor.

In many designs of the SST use of DC link is also employed. Value of capacitor at the DC link can be calculated as follows [21]:

$$
C_{D C}=\frac{V_{a-\text { peak }} X I_{n-\text { peak }}}{4 \pi X f_{g} X V_{D C} X \Delta V_{c}}
$$

where $V_{a-p e a k}$ is the output voltage peak value and $\mathrm{I}_{\mathrm{n} \text {-peak }}$ is the neutral current peak value.

\section{GENERAL OVERVIEW OF THE SST TECHNOLOGY}

Technology of the SST uses majorly converters to convert signal voltage from $\mathrm{AC}$ to $\mathrm{DC}$ and vise-versa, modulation technique to mitigate harmonics, filters at both input and output, control strategy for successful operation of the transformer. Technology of some of these units is briefly reviewed under this section of the paper.

\subsection{Review of converters technology}

The SST is an arrangement of converters separated or isolated by a high frequency transformer to function in a similar way the LFT does and with additional flexibilities and functionalities.

Converter enables the switching functions for the SST to operate. It does all the required necessary conversions such as: AC-DC, DC-DC, DC-AC and AC-AC [20].

a. AC-DC converter changes $\mathrm{AC}$ voltage to $\mathrm{DC}$ voltage. It is also called rectifier Examples of this type of converter are: Phase control rectifier, SMPS.

b. DC-DC converter also known as chopper. This type of converter steps up or down a DC voltage. There are types of this Converter: (i) True or Pure Sine Wave DC-AC Converter, (ii) Modified Sine Wave or Quasi Sine Wave DC-AC Converter, and (iii) Square Wave DC-AC Converter.

c. DC-AC converter also called Inverter. It converts DC voltage to an $\mathrm{AC}$ voltage.

d. AC-AC converter also known as cyclo-converter. It changes AC voltage level to another (either up or down). They are also called AC voltage regulator, matrix converter.

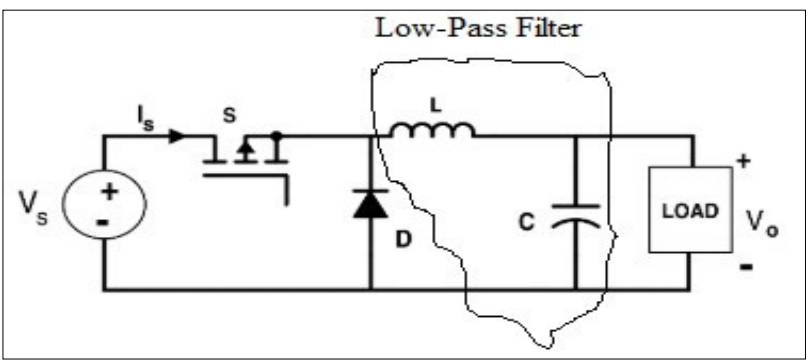

Fig. 10. Circuit diagram of Buck Converter 


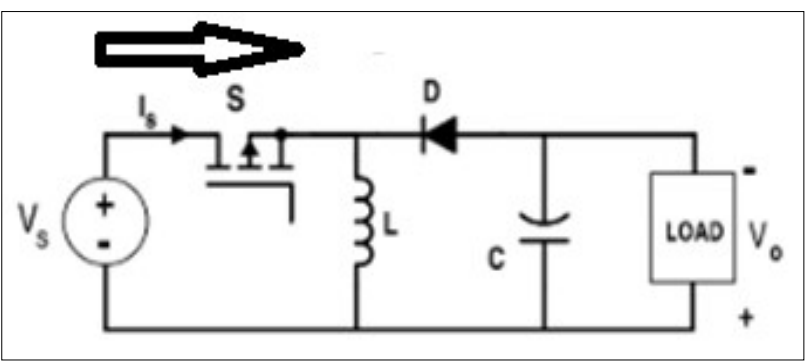

Fig. 11. Circuit diagram of Boost Converter

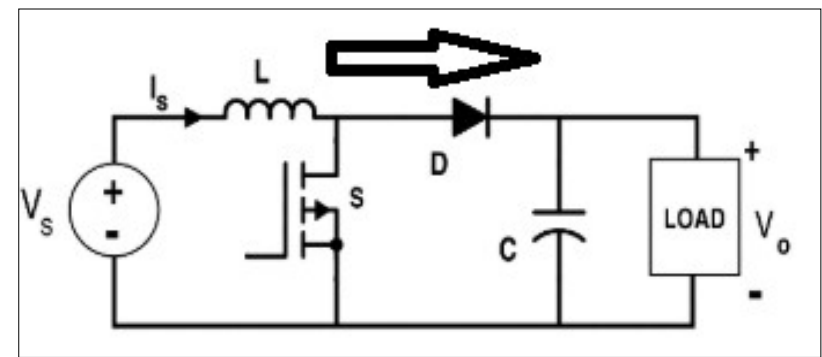

Fig. 12. Circuit diagram of Buck-Boost Converter

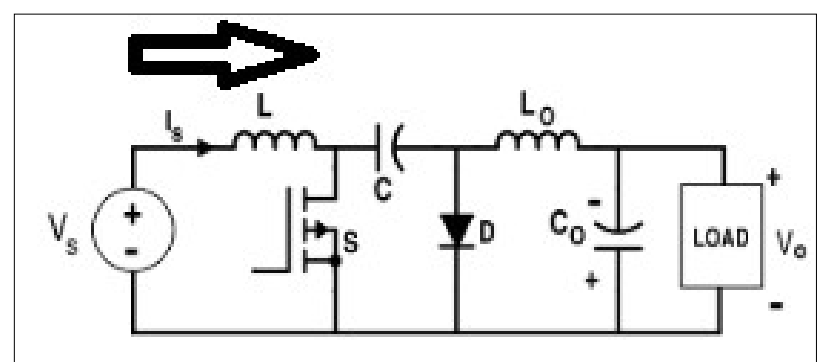

Fig. 13. Circuit diagram of Cuk Converter

In general, there are [22]:

a. Transformer-less converter: This consists of: Buck (step-down) converter. Buck converter is a basic transformer-less topology. It steps down an input voltage to an output voltage. Other types of the transformer-less converter are based on the buck converter in terms of analysis and design; Boost converter (step-up). It steps up input voltage; Buck-Boost Converter (step-down/step up). This converter steps up or down an input voltage to the output voltage; Cuk converter. It is dual of buck-boost converter. It consists of a capacitor that is used as main energy storage and transferring element that transfers power from primary to secondary stage; Full Bridge converter. This type of converter is the common among them. Its main areas of application are: DC motor drives, DC-AC (sine-wave) conversion in single-phase AC UPS systems and DC-AC (high intermediate frequency) conversion in switch-mode transform er-isolated DC power supplies. Circuit diagrams of this category of converter are as shown in Figures 10-14.

b. Isolated Converter. This type of converter includes a conventional transformer which provides electrical isolation and helps protects or minimize effect of faults. Isolated converters are grouped into two main groups depending on the means by which electrical isolation is provided: Unidirectional core excitation in which only positive quadrant (quadrant I) in Figure 15 is used and Bidirectional core excitation which means both positive and negative quadrant (quadrants I and III) of the B-H loop are used.

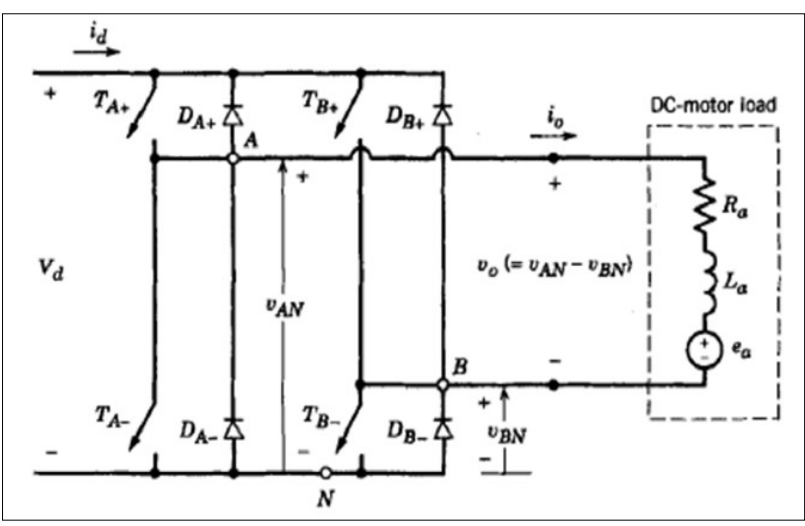

Fig. 14. Circuit diagram of Full Bridge Converter [22]

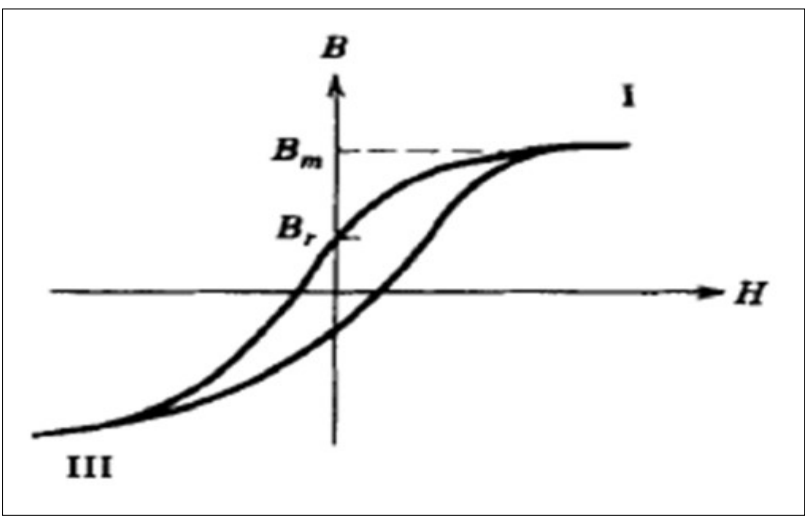

Fig. 15. A typical B-H Loop [22]

Some DC-DC converters that cannot provide Electric isolation can be modified to provide it. This can be achieved by means of unidirectional core excitation. Example: of such improvement are: Fly-back converters (Obtained from buck -boost converters). It is derived by a second winding to the inductor in the Buck-boost converter to achieve electrical isolation as in Figure 16; Forward converters (derived from Buck converters). This is derived from Buck converter. The voltage ratio in this form of converter depends on the duty ratio/modulation index in a similar manner to a Buck converter. The voltage transformation ratio is the same in either way of this type of converter. Circuit diagram of this converter is as shown in Figure 17.

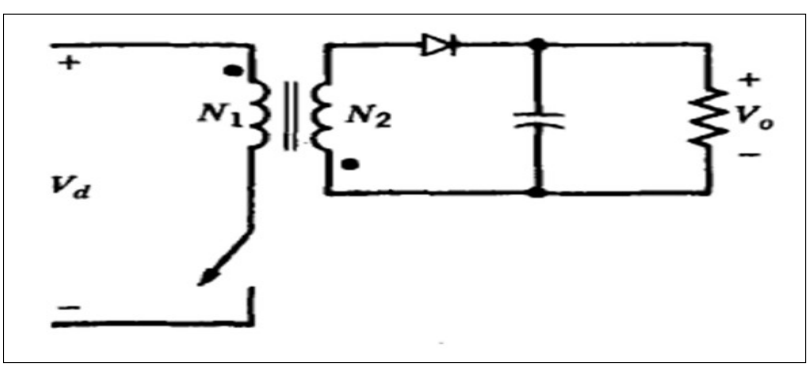

Fig. 16. Circuit diagram of Fly- Back Converter [22] 


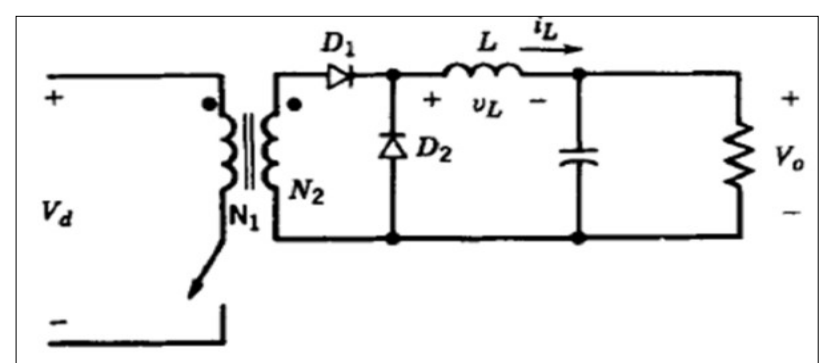

Fig. 17. Circuit diagram of Forward Converter [22]

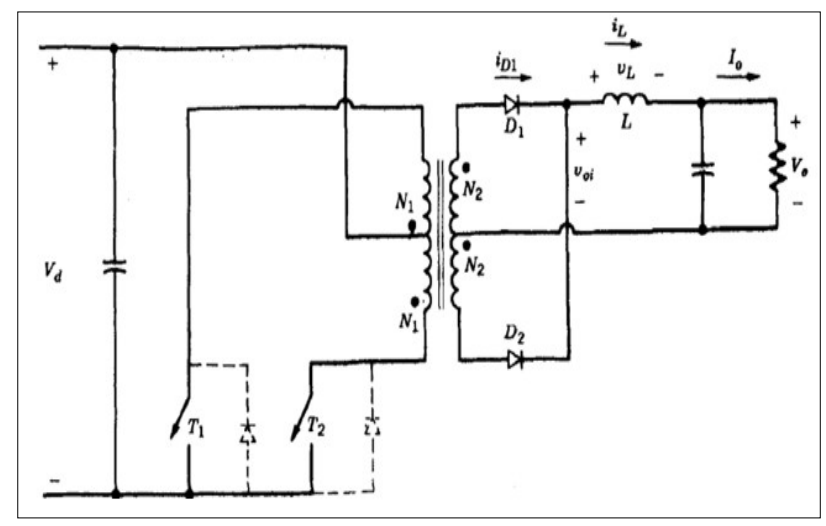

Fig.18. Circuit diagram of Push-pull Converter [22]

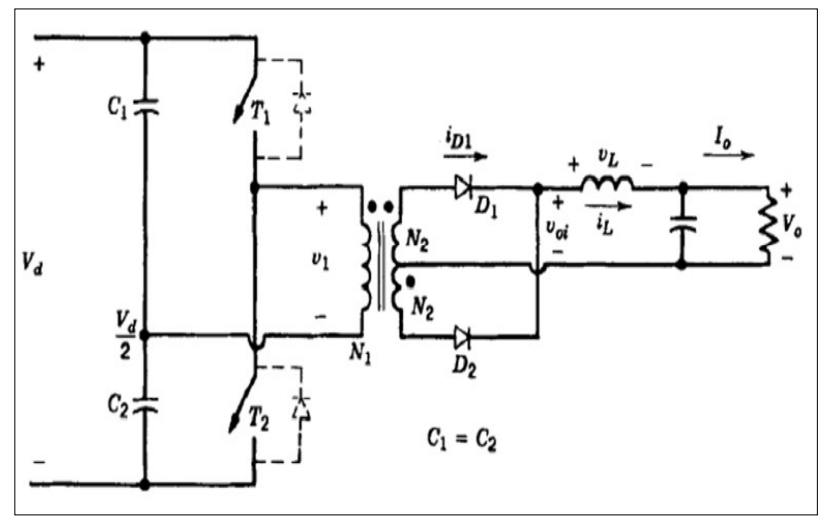

Fig. 19. Circuit diagram of Isolated Half Bridge Converter [22]

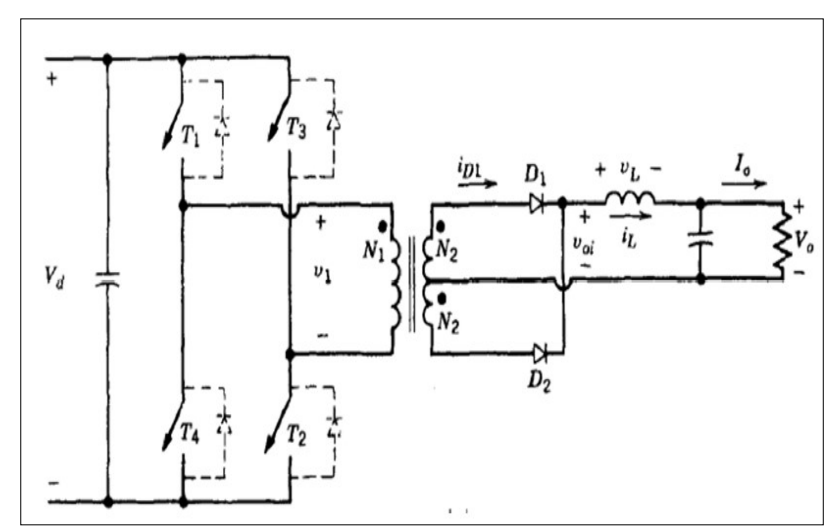

Fig. 20. Circuit diagram of Isolated Full Bridge Converter [22]

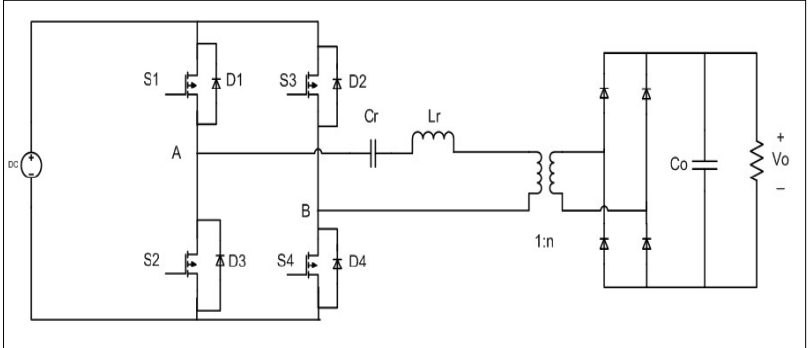

Fig. 21. Circuit diagram of Series Load Resonant Converter

Pulse Width Modulation is used to regulate output of these converters to achieve desired output. In order to obtain bidirectional core isolation as in SST, the following architectures are used to produce a square-wave form AC at the input of the high-frequency isolation transformer: Push-pull; Half Bridge; and Full Bridge. Circuit diagrams of these converters are as shown in Figures 18-20.

c. Series Resonant Converters (SRC). These are combination of converter topologies and switching strategies that result in zero-voltage and/or zerocurrent switching. Addition of Inductance ' $\mathrm{L}$ ' and Capacitance ' $C$ ' enables resonant behavior. An LC tank is used to cause oscillation of the capacitor voltage and inductor current. This results in Zero-Voltage Source (ZVS) and/or Zero-Current-Source (ZCS). Circuit diagram of these Converters is shown in Figure 21. These converters act as current source.

These converters can operate in the following modes: (i) Discontinuous-Conduction Mode (DCM) with $f_{s}<1 / 2 f_{0 .}$. In this case it operates at a frequency lower than the resonant frequency. Merits of this type of converter are: The switches naturally turn OFF at zero current and zero voltage, as the inductor current goes to zero; It has better controllability over no load conditions. However, it is associated with higher conduction losses due to large peaks in the inductor current every cycle. This is a result of the fact that the switching frequency is very low, and therefore it allows both the inductor current and capacitor voltage to fully resonate through a complete cycle; (ii) ContinuousConduction Mode (CCM) with $1 / 2 f_{o}<f_{s}<f_{0}$. In this mode, operation only takes place between half of the resonant frequency and the resonant frequency. Here, the switches turn $\mathrm{ON}$ at finite current and voltage, thus resulting in a turn-ON switching loss. However, it enables continuous inductor current. Turn OFF of the switches occurs naturally at ZCS and ZVS in this mode of operation; (iii) ContinuousConduction Mode with $f_{s}>f_{o}$

In this mode, operation is limited above the resonant frequency. Here, the switches turn $\mathrm{ON}$ at finite current, but turn $\mathrm{ON}$ at a zero current and zero voltage also. This operation creates significant turn-OFF switching loss. However, Lossless snubbers can be used in parallel with the switches to correct this problem.

d. Parallel Resonant Converters.

In this type of converters, the resonant tank is connected in parallel with the resonant capacitor ' $\mathrm{C}_{\mathrm{r} \text {. }}$ Circuit 
diagram of this converter is as shown in Figure 22. The Converters act as voltage source.

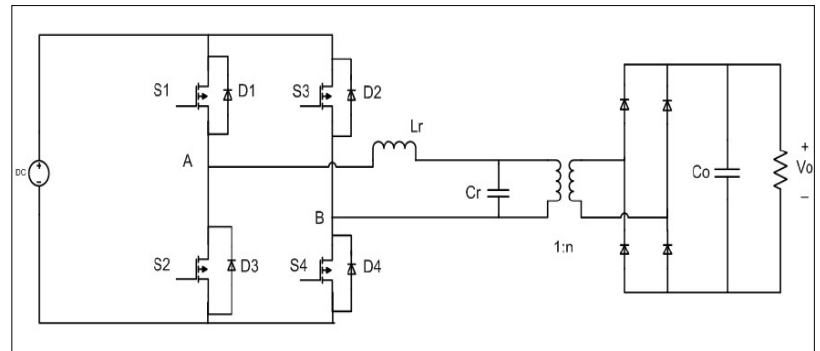

Fig. 22. Circuit diagram of Parallel Loaded Resonant Converter

These converters also operate in the three modes that the SLC operates.

While designing SST, two major forms of Converter topologies are being considered. These are [20]: (i) Single Active Bridge (SAB), and (ii) Dual Active Bridge (DAB) converters.

The $\mathrm{SAB}$ converters consist of two H-bridges: An active bridge at the input which converts $D C$ to $A C$; and passive output bridge which performs the $\mathrm{AC}$ to $\mathrm{DC}$ conversion. The HFT isolates the two bridges [20]. SAB converter circuit schematic is as shown in Figure 23.

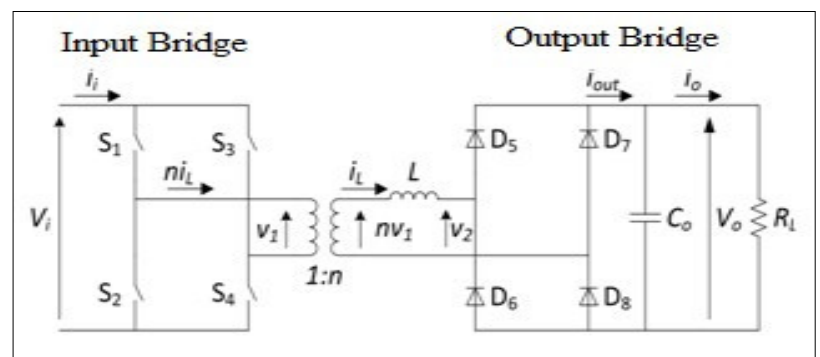

Fig. 23. SAB Converter Circuit Diagram

Insulated-Gate Bipolar Transistor (IGBT), Metal-Oxide Semiconductor Field Effect Transistor (MOSFET) and other semiconductor devices are used as switch $\left(S_{1}, S_{2}, S_{3}\right.$ and $\left.S_{4}\right)$. In the first SST prototype by $M$. McMurray, Silicon $(\mathrm{Si})$ bipolar transistors were used as switches. However, as at then, breakdown voltage for $\mathrm{Si}$ bipolar transistor was only about $100 \mathrm{~V}$. This and some technical reasons slow down penetration of SST in the distribution network. [23].

As earlier mentioned, a converter can operate at DCM and CCM under steady-state operation condition. When SAB is subjected to operate at DCM, plot of currents and voltages are as shown in Figure 24. It is observed in the Figure 24, that currents and voltages have half-wave symmetry.

The load current ' $\mathrm{I}_{0}$ ', Output Voltage ' $\mathrm{V}_{0}$ ' and Active power $\mathrm{P}_{0}$ at this operation of the $\mathrm{SAB}$ are given in the following expressions considering Figure 24 respectively [20].

$$
I_{o, D C M}=\frac{V_{i} \pi \alpha^{2}}{2 \omega L \pi^{2}}\left(\frac{V_{1}}{V_{0}}-1\right)
$$

$$
\begin{gathered}
V_{0, D C M}=V_{i} \frac{R_{L} \alpha^{2}}{4 \pi \omega L}\left[-1+\sqrt{1+\frac{8 \pi \omega L}{R_{L} \alpha^{2}}}\right] \\
P_{0, D C M}=\frac{V_{i} V_{0} \pi \alpha^{2}}{2 \pi^{2} \omega L}\left(\frac{V_{i}}{V_{0}}-1\right)
\end{gathered}
$$

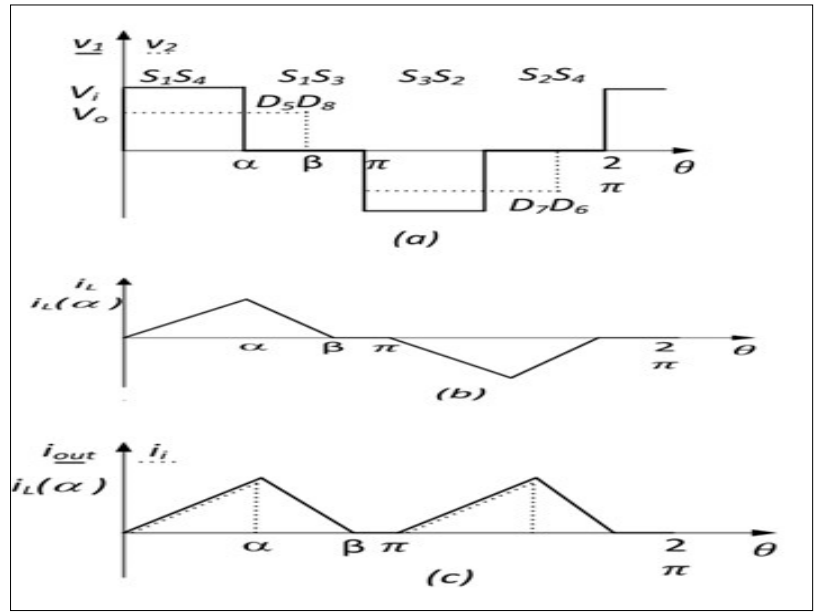

Fig. 24. SAB Converter Current and Voltage Waveforms under DCM [20]

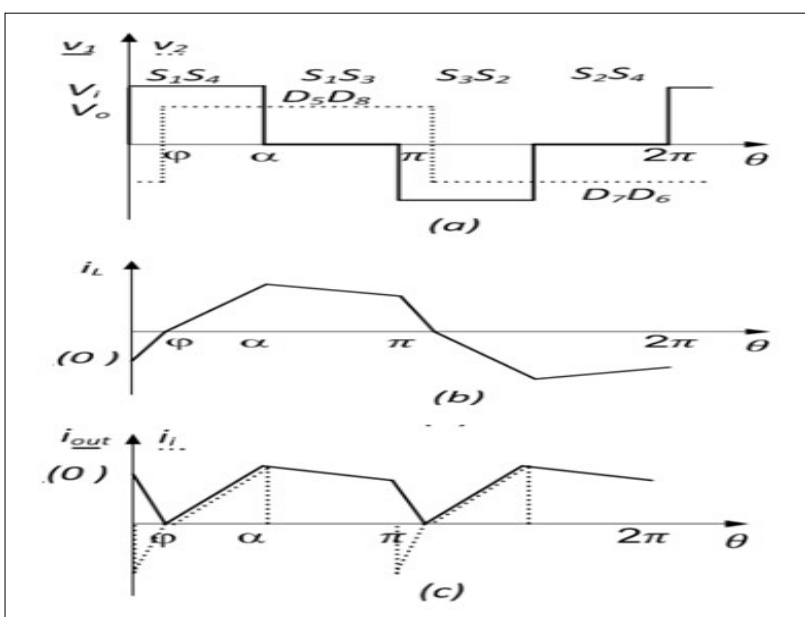

Fig. 25. SAB Converter Current and Voltage Waveforms under CCM [20]

On the other hand, under $\mathrm{CCM}$, the $\operatorname{SAB} \varphi$ voltages and currents are shown in Figure 25.

Under this condition, the current shift angle is calculated as shown in the following expression.

$$
\varphi=\frac{\pi}{2}\left(\frac{\alpha}{\pi}-\frac{V_{0}}{V_{1}}\right)
$$

The Load current ' $\mathrm{I}_{0}$ ' output voltage ' $\mathrm{V}_{0}$ ' and active power ' $\mathrm{P}_{0}$ ' delivered under the CCM condition are given by the following expressions [20].

$$
I_{0, C C M}=\frac{\pi V_{1}}{2 \omega L}\left[\frac{\alpha}{\pi}-\frac{1}{2}\left(\frac{\alpha}{\pi}\right)^{2}-\frac{1}{2}\left(\frac{V_{0}}{V_{1}}\right)^{2}\right]
$$




$$
\begin{gathered}
V_{0, C C M}=V_{1} \frac{2 \omega l}{\pi R_{L}}\left[-1+\sqrt{1+\left(\frac{2 \alpha}{\pi}-\frac{\alpha^{2}}{\pi^{2}}\right)^{2}\left(\frac{\pi R_{L}}{2 \omega l}\right)^{2}}\right] \\
P_{0, C C M}=\frac{\pi V_{i} V_{0}}{2 \omega l}\left[\frac{\alpha}{\pi}-\frac{1}{2}\left(\frac{\alpha}{\pi}\right)^{2}-\frac{1}{2}\left(\frac{V_{0}}{V_{i}}\right)^{2}\right]
\end{gathered}
$$

\subsection{Review of high frequency transformer technology}

It was earlier mentioned that the SST consisted of converters at both input and output being separated by the HFT. The use of HFT to provide galvanic isolation in the development of the SST is responsible for the achievement of the low size and light weight of the SST. This was expressed in equation (4).

To achieve HFT some important points are to be put into considerations. These include [24]: (i) proper magnetic material selection to achieve the required high power density and low losses; (ii) Thermal behavior to avoid breakdown especially for high-voltage and high-power designs; (iii) the winding configuration of the HFT can significantly affect its efficiency at high frequency; (iv) Insulation requirement at high-voltage operation should be considered.

Some magnetic materials suitable for high powers and their merits and demerits are tabulated in Table 1 [20].

\begin{tabular}{|c|c|c|c|}
\hline SNo & Material & Merit & Demerit \\
\hline 1 & Si steel & $\begin{array}{l}\text { (i) High } \\
\text { saturation flux } \\
\text { density } \\
\text { (ii) High } \\
\text { permeability }\end{array}$ & $\begin{array}{l}\text { (i) High losses } \\
\text { at high operat- } \\
\text { ing frequency }\end{array}$ \\
\hline 2 & Ferrite & $\begin{array}{l}\text { (i) Moderate } \\
\text { losses } \\
\text { (ii) Low cost }\end{array}$ & $\begin{array}{l}\text { (i) Low } \\
\text { saturated flux } \\
\text { density }\end{array}$ \\
\hline 3 & $\begin{array}{l}\mathrm{Fe}- \\
\text { Amorphous } \\
\text { alloy }\end{array}$ & $\begin{array}{l}\text { (i) Moderate } \\
\text { saturation flux } \\
\text { (ii) Moderate } \\
\text { losses }\end{array}$ & \\
\hline 4 & $\begin{array}{l}\text { Co- } \\
\text { amorphous } \\
\text { alloy }\end{array}$ & (i) Low losses & $\begin{array}{l}\text { (i) Limited } \\
\text { saturation flux } \\
\text { density }\end{array}$ \\
\hline 5 & $\begin{array}{l}\text { Nano } \\
\text { crystalline } \\
\text { alloy }\end{array}$ & $\begin{array}{l}\text { (i) High } \\
\text { saturation flux } \\
\text { (ii) Low losses }\end{array}$ & $\begin{array}{l}\text { (i) High cost } \\
\text { (ii) Limited } \\
\text { selection of } \\
\text { available } \\
\text { shapes }\end{array}$ \\
\hline
\end{tabular}

Table 2 Magnetic materials comparison

So far, Fe-amorphous is considered by some SST designers as the best. This is because in addition to other merits, its saturation flux density reaches $1.56 \mathrm{~T}$. Transformer structure has influence on power density and efficiency. Therefore, the structure choice is very important aspect of the SST design. Of the two transformer structures (solenoidal and coaxial), solenoidal is the most used because of its following advantages [20].
(i) Easier to design
(ii) Easier to manufacture
(iii) Lower costs

Two effects, skin and proximity effects must be put into consideration while designing an HFT. Skin effect is the tendency of an alternating electric current to distribute within a conductor such that the current density is largest near the surface of the conductor, and decreases with greater depths in the conductor.

This effect is demonstrated in Figure 25.

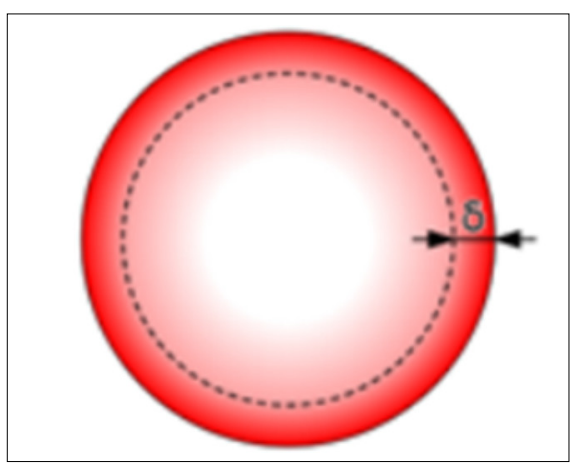

Fig. 26. Skin depth in a section of a conductor [20]

At high frequencies, the skin depth is smaller and therefore, the skin effect causes increase in the effective resistance of the conductor, thus, reducing the effective cross sectional area of the conductor. Skin depth is the depth below the surface of the conductor at which the current density has fallen to I/e (about $37 \%$ of J) The current density ' $J$ ' and skin depth ' $\delta$ ' are respectively given as follows [20]:

$$
\begin{gathered}
J=J_{s} e^{-d / \delta} \\
\delta=\sqrt{\frac{2 \rho}{\omega \mu}}
\end{gathered}
$$

Where $J_{s}$ is the current density on the surface, $d$ is the distance from surface and ' $\delta$ ' is the skin depth, $\rho$ is the resistivity of the conductor and

$\mu=\mu_{0} \mu_{\mathrm{r}}$ is the permeability.

Proximity effect occurs when more conductors carrying alternating current are nearby. The distribution of current within a conductor will be constrained to smaller regions if current is flowing through one or more other nearby conductors. The resulting current crowding is referred to as the proximity effect. The crowding increases effective resistance of the circuit and it increases with the increase in frequency [20].

Proximity effect is illustrated in Figure 26.

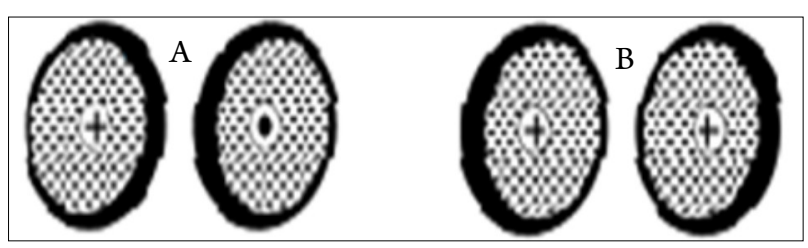

Fig. 27. Proximity effect with opposite (a) and same (b) current directions 
To attenuate the skin and proximity effects use of Litz wire is normally employed by the designers of HFT. Litz wire consists of many thin wire strands, individually insulated and twisted or woven together, often in several levels. Figure 27 shows an example of Litz wire.

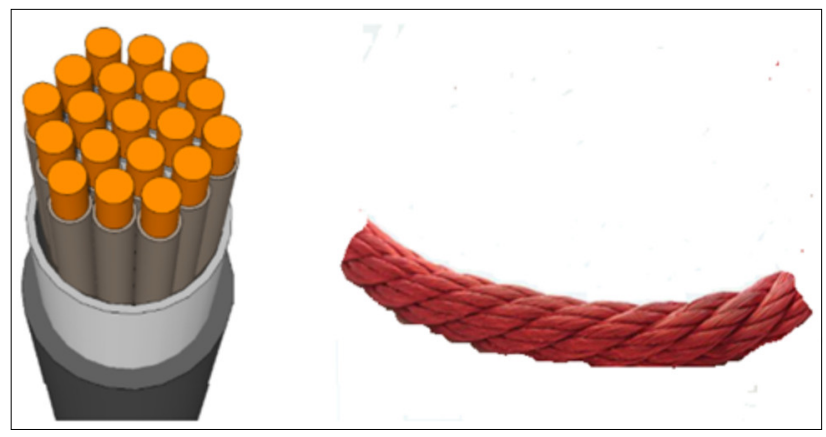

Fig. 28. Example of Litz wire

The HFT is the main component being used in the design of the SST to achieve reduction in size, volume and even cost. Many attempts have been made to optimize the HFT design for application in the SST such in [25-30].

\subsection{Control mechanism}

SST uses power converters in its implementation. This subsection will discuss briefly about power converters control mechanisms that are usually employed while designing SST. One of the control mechanisms for SST is a closed-loop controller. This controller in usually used in designing an SST to regulate the converter output voltage and compensate source or load disturbances. In this type of controller, the error between output voltage and its reference is minimized or eliminated. The error is the in accuracy between actual output and the interference.

To design a desired power converter controller, the following methodologies are adapted.

(i) develop small signal model around the operating point of a steady-state

(ii) get where the control-to-output transfer function takes place in the converter

(iii) specify the loop gain expected depending on the design specifications

(iv) Design controller transfer function to match the desired loop gain

Proportional-Integral (PI) controller is the most commonly used controller for power converters. Lead Compensator (LC) is an alternative to controller for power converter [31]. The compensator increases the loop-gain phase-margin. Disadvantage of the two controllers (PI and LC) which are mainly designed for a single operating point is that, they achieve only infinite gain at DC. Therefore, it is difficult to reach zero steady-state error when the disturbance or reference is an AC signal at low frequency [32]. Gain-Scheduling Control (GSC) is an improved control technique compared to PI and LC. Alternative to GSC is Adaptive Control (AdC). The AdC adjusts control parameters. To achieve better performance in GSC, on-line parameter is employed. Usually, adaptive control is employed on a system when its structure is known while its parameters are unknown or varying [32]. Other nonlinear methods of power converter controller implementation are [33] : i) Back-stepping based on Lyapunov function and ii) Fuzzy logic.

\subsection{Modulation Technique}

Modulation techniques for power converters are developed in the following form [34-36].

(i) Voltage Level Based Algorithms (VLBA) - This method operates in time domain. Pulse Width Modulation (PWM) is the most used voltage level based modulation technique; this is because of its high performance, simplicity, fixed switching frequency and easy digital and analog implementation.

(ii) Space Vector Based Algorithms (SVBA) -- In this modulation technique, the reference voltage is represented by a reference vector. Unlike in the time domain where a phase reference is used, here reference vector is used to compute the switching times and states. In SVBA, number of redundant switching states and complexity of selecting states increase with increase in number of levels.

Although there are several space vector based algorithms, carrier based PWM is a dominant modulation technique in converters operations. This is because, it requires a reference signal, carrier signals, and a simple comparator for the gating signals. On the other hand, Space vector based algorithms require at least three stages: a stage to select the vectors for modulation, a stage to compute the duty cycle and a stage where the sequence for the vectors is generated. This means that the space vector algorithms have higher hardware requirements than the PWM techniques.

\subsection{Filter}

Filters are used at input or output stage of SST to attenuate propagation of harmonics [37]. A typical input or output filter is shown in Figure 27.

A filter for SST can either be composed of LC (Inductor, Capacitor) or LCR (Inductor, Capacitor and Resistor). In Figure 27, an LCC three order filter topology composed of LCR is shown. The LCR capability out-weighs that of the LC. This is because, the LCR can better restraint high frequency interference and can reduce gain in resonance peak point [37].

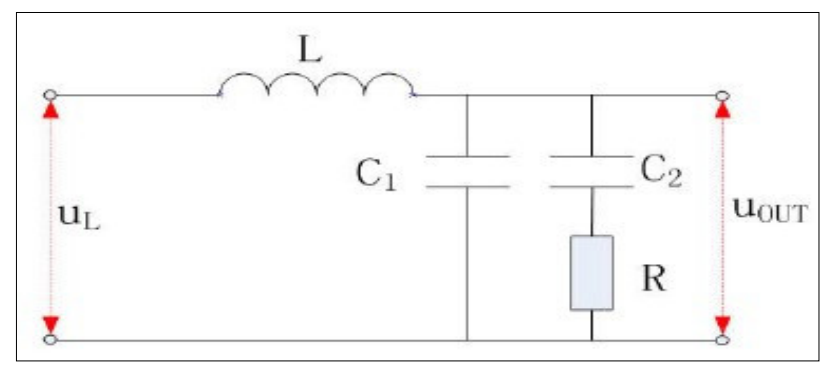

Fig. 29. A structure typical Filter for SST [37] 
Open loop transfer function of the filter in Figure 27 is given as follows [37]:

$$
\begin{aligned}
& G(s)=\frac{u_{\text {OUT }(s)}}{u_{L}(s)} \\
& =\frac{s R C_{2}+1}{S^{3} R C_{1} C_{2} L+S^{2}\left(C_{1}+C_{2}\right) L+S R C_{2}+1}
\end{aligned}
$$

Usually $C_{2}$ equals $1 / 3$ or $1 / 2 C_{1}$. Assuming, $C_{1}=C_{2}=C$, therefore, eqn. (21) can be simplified as follows [37]:

$$
\begin{aligned}
& G(s)=\frac{u_{O U T(s)}}{u_{L}(s)} \\
& =\frac{s R C_{2}+1}{S^{3} R C^{2} L+2 S^{2} C L+S R C+1}
\end{aligned}
$$

Natural oscillation frequency and damping ration can be expressed as follows considering Figure 27 respectively [37].

$$
\begin{aligned}
& \omega_{n}=\frac{1}{\sqrt{L C}} \\
& \xi=\frac{1}{R} \sqrt{\frac{L}{C}}
\end{aligned}
$$

where, $\xi, \mathrm{R}$, are damping ratio and damping resistor respective.

It can be deduced from eqn. (20) that, damping ratio is inversily proportional to damping resistor so long $\mathrm{L}$ and $\mathrm{C}$ are kept constant. Proper choice of the damping resistor is very important in the design of the filter. This is because the resistor as it comsumps power, it affects effficiency of the SST.

\section{OBSTACLE OF OST TO UNIVERSAL ACCEPTANCE}

It is good to re-emphasize that critical need to increase energy efficiency and safety in the electrical industry is one of the major problems being faced by Electrical power industry that necessate search for solution. Other problems are: Inherent nature of renewable energy, ii) traditional monitoring schemes (e.g. SCADA) may not provide enough fidelity to adequately monitor generation.

In view of the foregoing problems, SST is proposed to replace LFT due to some of its advantages as enumerated earlier. However, SST does not penetrate the electric network globally. This is due to the following [38]:

(i) Reliability: LFT has been seen to be highly reliable. It operates in harsh environment. On ther other hand, SST due to use of semiconductor may not be as reliable as the LFT. This change can be significantly reduced.

(ii) Cost : Cost is a factor that is putting more confidence in the minds of the users of electricity and the utility as regard use of LFT as against the SST. Use of semiconductors and other devices, requires huge maintenace cost. However, researchers may inprove on this area.

(iii) Efficiency : The National Electrical Manufacturers Association's class 1 efficiency rating indicates that, a 30kVA LFT must have an efficiency of greater than $97.5 \%$. A comparable SST to this LFT may have an efficiency of far less than this value. SST involves many convresion stages which sometimes reduces its overal efficiency. However, this could be a thing of the fast in a near future.

\section{FUTURE RESEARCH}

The following are some of the areas require rigorous research to enable the SST completely replce the LFT in the electric network

(i) SST reliability improvement

(ii) Improvemment of SST protection

(iii) Use of Low voltage devices to improve efficiency

(iv) In caase of use Multi-level converters in the design of the SST, optimum number of level should be identified.

(v) Possibility of enabling low loss high current MF interconnections opportunity

(vi) Selection of propor insulation materials under MF voltage Stress.

\section{CONCLUSION}

The paper glanced in the SST technology with the view to identifying where its technology started, where is it? And how can it be improved in the future. It is evident that with the areas of cries against SST being raised by researchers resolved, the transformer can replace the LFT in the electric network.

\section{AUTHOR INFORMATION}

Corresponding Author

* Phone : +2348055551020

Email : mambilla2000@yahoo.com

ORCID

Bashir Musa Umar : 0000-0002-0789-8525

Musa Mohammed : 0000-0003-3463-8208

\section{ACKNOWLEDGEMENTS}

We acknowledged contribution of Sana'a da ilmi foundation, Nigeria for supporting the work with a grant.

\section{REFERENCES}

[1] N. K. Sinha and M. M. Gupta, Introduction to Microcontrollers. 2001.

[2] R. Strzelecki and G. Benysek, "Power electronics in smart electrical energy networks," Power Syst., vol. 34, 2008, doi: 10.1007/978-1-84800-318-7.

[3] J. S. Lai, W. H. Lai, S. R. Moon, L. Zhang, and A. Maitra, "A $15-\mathrm{kV}$ class intelligent universal transformer for utility applications," in Conference Proceedings IEEE Applied Power Electronics Conference and Exposition - APEC, 2016, vol. 2016-May, pp. 19741981, doi: 10.1109/APEC.2016.7468139. 
[4] S. Bhuskute, M. V. S. Pawar, and M. D. S. Patil, "Modeling and Simulation of Solid-State Transformer," (C) Int. J. Eng. Sci. Res. Technol., vol. 5, no. 3, pp. 551558, 2016, doi: 10.5281/zenodo.48248.

[5] P. K. Preetha and P. S. Chandramohanan Nair, "Modified distribution transformer for enhancing power quality in distribution systems," Int. J. Power Electron. Drive Syst., vol. 7, no. 4, pp. 1386-1392, 2016, doi: 10.11591/ijpeds.v7i4.pp1386-1392.

[6] V. Z. Manusov, M. K. Nazarov, and D. M. Ivanov, "Analyses of Electrical Parameters of Power Transformers with Superconducting Windings," in International Conference of Young Specialists on Micro/Nanotechnologies and Electron Devices, EDM, 2019, vol. 2019-June, pp. 547-551, doi: 10.1109/ EDM.2019.8823091.

[7] R. C. Mala, S. Tripathy, S. Tadepalli, and D. R. Reddy, "Performance analysis of three phase solid state transformers," 2012 Int. Conf. Devices, Circuits Syst. ICDCS 2012, pp. 486-490, 2012, doi: 10.1109/ ICDCSyst.2012.6188762.

[8] T. Gajowik, C. Sobol, S. Stynski, and M. Malinowski, "Post-fault operation of hybrid DC-DC converter for Solid-State Transformer," in Proceedings IECON 2017 - 43rd Annual Conference of the IEEE Industrial Electronics Society, 2017, vol. 2017-Janua, pp. 53735379, doi: 10.1109/IECON.2017.8216931.

[9] J. E. Huber and J. W. Kolar, "Solid-State Transformers: On the Origins and Evolution of Key Concepts," IEEE Ind. Electron. Mag., vol. 10, no. 3, pp. 19-28, 2016, doi: 10.1109/MIE.2016.2588878.

[10] F. Vaca-Urbano, M. S. Alvarez-Alvarado, A. A. Recalde, and F. Moncayo-Rea, "Solid-State Transformer for Energy Efficiency Enhancement," in Research Trends and Challenges in Smart Grids, IntechOpen, 2020.

[11] A. Abu-Siada, J. Budiri, and A. Abdou, "Solid State Transformers Topologies, Controllers, and Applications: State-of-the-Art Literature Review," Electronics, vol. 7, no. 298, pp. 1-18, Nov. 2018, doi: 10.3390 /electronics7110298.

[12] S. Bird and S. Doss, "Intelligent universal transfomer desing and applications," in 20 th International Conference on Electricity Distribution Paper 1032, 2009, no. 1032, pp. 8-11.

[13] U. Tahir et al., "Design of three phase solid state transformer deployed within multi-stage power switching converters," Appl. Sci., vol. 9, no. 17, 2019, doi: 10.3390/app9173545.

[14] X. She and A. Huang, "Solid state transformer in the future smart electrical system,” 2013.

[15] A. Rehman and M. Ashraf, "Design and Analysis of PWM Inverter for 100KVA Solid State Transformer in a Distribution System,” IEEE Access, vol. 7, pp. 140152 -140168, 2019, doi: 10.1109/access.2019.2942422.

[16] F. Bignucolo, M. Bertoluzzo, and C. Fontana, "Applications of the solid state transformer concept in the electrical power system," in 2015 AEIT International Annual Conference, AEIT 2015, 2015, no. February 2017, doi: 10.1109/AEIT.2015.7415235.

[17] N. Verma, N. Singh, and S. Yadav, "Solid state transformer for electrical system: Challenges and solution," in 2018 2nd International Conference on Electronics, Materials Engineering and NanoTechnology, IEMENTech 2018, 2018, pp. 1-5, doi: 10.1109/IEMENTECH.2018.8465315.

[18] M. Ebrahim and A. Firouzjaee, "Advanced modeling of solid state transformer," Universitat Politècnica de Catalunya, 2018.

[19] A. M. Elrajoubi and S. S. Ang, "High-frequency transformer review and design for low-power solid-state transformer topology," 2019 IEEE Texas Power Energy Conf. TPEC 2019, pp. 1-6, 2019, doi: 10.1109/TPEC.2019.8662131.

[20] C. Fontana, "Solid-State Transformer," Universita Degli Studi Di Padova, 2018.

[21] W. C. Alves and L. M. F. Morais, "Design of an Highly Efficient AC-DC-AC Three-Phase Converter Using $\mathrm{SiC}$ for UPS Applications,” pp. 1-19, 2018, doi: 10.3390/electronics7120425.

[22] N. Mohan, T. D. Underland, and W. P. Robbins, Power Electronics - Converters, Applications, and Design, Third Edit. Minneapolis MN: John Wiley \& Sons, Inc, 2003.

[23] P. A. Q. Huang, "Solid State Transformer and FREEDM System Power Management Strategies," 2015.

[24] M. E. Adabi and J. A. Martinez-Velasco, "Solid state transformer technologies and applications: A bibliographical survey," AIMS Energy, vol. 6, no. 2, pp. 291338, 2018, doi: 10.3934/ENERGY.2018.2.291.

[25] S. S. Baek, S. Bhattacharya, B. Cougo, and G. Ortiz, "Accurate equivalent circuit modeling of a mediumvoltage and high-frequency coaxial winding DC-link transformer for solid state transformer applications," 2012 IEEE Energy Convers. Congr. Expo. ECCE 2012, pp. 1439-1446, 2012, doi: 10.1109/ ECCE.2012.6342645.

[26] G. Ortiz, M. Leibl, J. W. Kolar, and O. Apeldoorn, "Medium Frequency Transformers for Solid-StateTransformer Applications - Design and Experimental Verification,” IEEE Access, pp. 1285-1290, 2013.

[27] M. A. Bahmani, T. Thiringer, A. Rabiei, and T. Abdulahovic, "Comparative Study of a Multi-MW High-Power Density DC Transformer with an Optimized High-Frequency Magnetics in All-DC Offshore Wind Farm," in IEEE Transactions on Power Delivery, 2016, vol. 31, no. 2, pp. 857-866, doi: 10.1109/TPWRD.2015.2494883.

[28] K. S. Alam, L. A. R. Tria, D. Zhang, and M. F. Rahman, "Design of a Bi-Directional DC-DC Converter for Solid-State Transformer ( SST ) Application by Exploiting the Shoot Through Mode," 2016, pp. 276-281.

[29] M. Leibl, S. Member, G. O. Member, and J. W. K. Fellow, "Design and Experimental Analysis of a Medium Frequency Transformer for Solid-State Transformer Applications," vol. 6777, no. c, 2016, doi: 10.1109/JESTPE.2016.2623679.

[30] H. Beiranvand and A. Rokrok, E. Rezaeeealam, B. and Kumar, "Optimal Design of Medium-Frequency 
Transformers for Solid-State Transformer Applications," in 8th Power Electronics, Drive Systems \& Technologies (PEDSTC 2017), 2017, pp. 14-16.

[31] A. R. Alonso, J. Sebastian, D. G. Lamar, M. M. Hernando, and A. Vazquez, "An overall study of a Dual Active Bridge for bidirectional DC/DC conversion," 2010 IEEE Energy Convers. Congr. Expo. ECCE 2010 - Proc., pp. 1129-1135, 2010, doi: 10.1109/ ECCE.2010.5617847.

[32] H. Zhou, A. M. Khambadkone, and X. Kong, "Passivity -based control for an interleaved current-fed full-bridge converter with a wide operating range using the Brayton-Moser form," IEEE Trans. Power Electron., vol. 24, no. 9, pp. 2047-2056, 2009, doi: 10.1109/ TPEL.2009.2021421.

[33] C. Cecati, F. Ciancetta, and P. Siano, "A multilevel inverter for photovoltaic systems with fuzzy logic control," IEEE Trans. Ind. Electron., vol. 57, no. 12, pp. 4115-4125, 2010, doi: 10.1109/TIE.2010.2044119.

[34] L. G. Franquelo, J. I. Leon, and E. Dominguez, "Recent advances in high-power industrial applications," IEEE Int. Symp. Ind. Electron., pp. 5-10, 2010, doi: 10.1109/ISIE.2010.5637656.
[35] V. H. Prasad, D. Boroyevich, and R. Zhang, "Analysis and comparison of space vector modulation schemes for a four-leg voltage source inverter," in Conference Proceedings - IEEE Applied Power Electronics Conference and Exposition - APEC, 1997, vol. 2, pp. 864-871, doi: 10.1109/apec.1997.575747.

[36] M. Ramaprasad Reddy, T. Brahmananda Reddy, and B. Brahmaiah, "Discrete space vector modulation algorithm based vector controlled induction motor drive," J. Electr. Eng., vol. 14, no. 2, pp. 371-377, 2014.

[37] X. Lv, Y. Xu, X. Zhang, and T. Zhou, "Study on a new topology of power electronic transformer," in $20172 \mathrm{nd}$ International Conference on Power and Renewable Energy, ICPRE 2017, 2018, vol. 10, no. 11, pp. 281285, doi: 10.1109/ICPRE.2017.8390543.

[38] K. S. Gadgil, “SOLID-STATE TRANSFORMERS," no. 6, pp. 320-324, 2016.

This article is licensed under a Creative Commons Attriution 4.0 International License. 